\title{
Stock Analysis Strategy for US's Stock Market Based on Risk, Profitability, and Market Value Insights
}

\author{
Jiukun $\mathrm{Chu}^{1, *, a, \dagger}$, Yizi Jin ${ }^{2, *, b, \dagger}$, Han Zhang ${ }^{3, *, c, \dagger}$ \\ ${ }^{1}$ Upper Canada CollegeM2N 4 W6 Toronto, Canada \\ ${ }^{2}$ High School Affiliated to Shanghai Jiao Tong University, IB Center, 200438, Shanghai, China \\ ${ }^{3}$ Shanghai IVY High School, 201315, Shanghai, China \\ "Corresponding authors.Email: ${ }^{a}$ alan.chu@ucc.on.ca ; ${ }^{b}$ jinyizi@jdfzib.com; ${ }^{2}$ Zhanghan2004@163.com \\ ${ }^{\dagger}$ These authors contributed equally.
}

\begin{abstract}
As there has been a great improvement in citizens' living standards, consumer discretionary is occupying a larger and larger market. This article is trying to analyze some big consumer discretionary companies through their recent performance on the stock market. There are nine companies, which are Kweichow Moutai, TSLA, China Gold, Starbucks, Hilton, Estee Lauder, Nike, General Motor, and Amazon. This article separated the companies into three frameworks, found financial data on websites and calculated different ratios related to these companies' risk, profitability, and market value. This article then gave out some possible investors and unlikely investors of them. The conclusion is that Kweichow Moutai, Estee Lauder, and Nike performed best in their own frameworks. Our work is to describe the current situation of different kinds of consumer discretionary firms through our chosen samples. The paper presents our research results about the topic.
\end{abstract}

Keywords: frameworks, risk, profitability, market value, possible investors

\section{INTRODUCTION}

Stock investment has attracted extensive public attention in the past few decades. It is a kind of securities investment, and the buyer makes a profit through the price difference between buying and selling stocks. There are many great investors that are famous in the world, such as Benjamin Graham, Warren E. Buffett. They are all good examples for us to learn. For example, Warren E. Buffet, the stock he invested of GEICO, a government employee insurance company, earns a profit of US $\$ 7$ billion with only an investment of US $\$ 45$ million. His great success is partly because he is good at analyzing stocks. Learning to analyze stocks will bring great benefits to people. In daily life, investment has a great impact on people. People can become rich by investing in good stocks, and thus more and more people in society begin to learn to invest in stocks.

The purpose of this article is to calculate and analyze whether these companies are worth investing through the basic data in the financial statements of several companies.
Many studies conduct research about investment analysis. Lo [1] used a large sample of hedge funds and found strong evidence of liquidity timing. The article highlights the importance of understanding and incorporating market liquidity conditions in investment decision making.

In 1929, the American stock market crashed, and Benjamin Graham's investment portfolio suffered huge losses. Graham worked hard to find ways to avoid investment losses and increase the success rate of investment. After the research, Graham put forward the idea of value investment, and compiled the research results into a masterpiece called the Investor's Bible "Securities Analysis" [2]. The book "Securities Analysis" published in 1934 marked the birth of the securities analysis industry and the beginning of value investment theory research.

In 1938, John Williams published the book "Investment Value Theory" [3], he first proposed the concept of the intrinsic value of stocks. The intrinsic value of stocks is equal to the discounted value of dividends and interest that stockholders will receive in the future, which comprehensively puts forward the 
theory of investment value. This is the theoretical basis for measuring the value of stocks, and Williams' theory uncovers the mystery of the growth of corporate value. Since the DCF (Discounted Cash Flow) model needs to predict future cash flow, the evaluation result depends on the prediction of future cash flow and the selection of discount coefficient.

In 1968, Ball and Brown [4] were the first to study the relationship between accounting surplus and excess stock returns, creating a precedent for the study of the relationship between financial information and stock prices. They conducted a research on 261 companies listed on the New York Stock Exchange and found that from 1946 to 1965 , from 12 months before to 6 months after the company's profit information was disclosed, there was a difference between the sign of profit changes and the sign of excess stock returns. This is the first time that people have found evidence of a correlation between corporate earnings and company stock returns. In 1989, Lev [5] reviewed and summarized relevant important literature in the United States in the past 20 years, and found that the explanation of accounting earnings for stock returns was not as high as expected.

Basu was the first to use the price-earnings ratio index to conduct an empirical analysis of value investment strategies. In 1977, Basu [6] used the CAPM model to conclude that stocks with low price-to-earnings ratios can obtain excess returns. In 1983, Goodman and Peavy reached the same conclusion by using the $\mathrm{P} / \mathrm{E}$ ratio analysis of different industries [7]. . In 1985, the research results of Levy and Lerman [8] using the random dominance theory also supported the conclusion that stocks with low price-earnings ratios can obtain excess returns. In 1987, Senchack and Martin [9] found that securities portfolios with low PS (market-to-sales ratio) outperformed the market average, and portfolios of securities with low PE (price-to-earnings ratio) can bring more stable income than portfolios with low PS securities. And using a portfolio of securities with a low PS ratio, the stability of income is more related to the size of the company. In 1988, Jacobs and Levy [10] studied the impact of PS on stocks' investment yield from 1978 to 1986 and found that the two are significantly correlated

Throughout the analysis process, this article used 3 key factors in determining the potential of our stocks: profitability, risk, and market value. By gathering ratios and percentages for these 3 factors this article were able to come to conclusions with our final analysis. Our topic of the study is to analyze the nine companies' financial situation and their possible investors. To achieve the goal, this article got data from websites like Yahoo Finance and calculated different ratios related to these companies' risk, profitability, and market value. The result is that for risk factors, stock investors like Kweichow Moutai most and General Motors least; for profitability factors, they like General Motors most and Hilton least; for market value, they like Kweichow Moutai most and Hilton least.

In this article, the reminder of the paper is organized as follows. Section 2 presents the firm description about this company. Then, in Section 3, this article introduce the investment analysis. In Section 4, this article summarize our results in the Conclusion.

\section{FIRM DESCRIPTION}

In this section, this article separate the nine companies into three frameworks. The first framework is named KTC, including Kweichow Moutai, TSLA, and China Gold. The second framework is the SHE framework, including Starbucks, Hilton, and Estee Lauder. The third one is the NGA framework, combining Nike, General Motor, and Amazon.

\subsection{KTC framework}

The three firms this article chose were Kweichow Moutai, TSLA, and China Gold. Kweichow Moutai is mainly engaged in the production and sales of Kweichow Maotai liquor series products, as well as the production and sales of beverages, food and packaging material. TSLA is an American electric vehicle and energy company, producing and selling electric vehicles, solar panels, and energy storage equipment. And China gold is the largest gold enterprise in China. It is mainly engaged in the exploration and design, resource development, product production and sales of metals such as gold, silver, copper. All these three companies produce consumer discretionary goods.

\subsection{SHE framework}

The first firm this article analyzed was Starbucks Corporation, listed on the stock market in the USA. Starbucks Corporation has tens of thousands of chain stores all over the world, selling coffee and desserts. The second company was Hilton Worldwide Holdings Inc. Hilton is famous for its excellent hotel services, whose business was influenced by the COVID-19 so much last year since most people just stayed at home. The third firm was the Estee Lauder Companies Inc. It is one of the world's largest entry lux companies, selling skin care, cosmetics, and perfume.

\subsection{NGA framework}

Nike, Inc. is an American multinational corporation that is engaged in the design, development, manufacturing, and worldwide marketing and sales of footwear, apparel, equipment, accessories, and services. Amazon.com, Inc. is an American multinational technology company that focuses on e-commerce, cloud computing, digital streaming, and artificial intelligence. It is one of the Big Five companies in the U.S. 
information technology industry, along with Google, Apple, Microsoft, and Facebook. General Motors Company is an American multinational corporation headquartered in Detroit, Michigan that designs, manufactures, markets, and distributes vehicles and vehicle parts, and sells financial services.

\section{INVESTMENT ANALYSIS}

Generally, this article chose 9 stocks to analyze the types of investments and this article divided these analyses into three parts: Risk, Profitability, and Market value.

\subsection{KTC framework}

\section{KTC}

Moutai-TSLA-China, Gold) framework companies Kweichow Moutai, TSLA, and China Gold.

For risk factors, this article can estimate whether these stocks are risky or not by several factors. This article used current ratios, quick ratios, debt ratios, debt/equity ratios and beta coefficient for analysis. The current ratio represents the ability of a company to pay its debt. If the current ratio is too small, it means that the company's solvency is not strong. The current ratio for Kweichow Moutai is 5.75, for TSLA the current ratio is 1.875 and for China Gold, it is 2.336. The quick ratio represents the immediate debt paying ability of the company. The quick ratio for Kweichow Moutai is 4.83, for TSLA the quick ratio is 1.59 and for China Gold, it is 1.219. The debt ratio is used to measure how much debt a company owes. The debt ratio for Kweichow Moutai is 0.214 , for TSLA the debt ratio is 0.546 and for China Gold, it is 0.414 . Debt to equity ratio shows the extent to which the company is willing to borrow rather than use its own equity. The Debt to equity ratio for Kweichow Moutai is 0.27 , for TSLA the Debt to equity ratio is 1.19 and for China Gold, it is 0.71 . For beta coefficient, If it is less than 1 , the risk is relatively small; on the contrary, the greater the beta coefficient, the greater the risk is. The beta coefficient for Kweichow Moutai is 0.85 , for TSLA the beta coefficient is 2.06 and for China Gold, it is 2.01.

Table 1. Risk evaluation for different stocks.

\begin{tabular}{llll}
\hline Ratios & $\begin{array}{l}\text { Kweichow } \\
\text { Moutai }\end{array}$ & TSLA & China Gold \\
\hline Market Cap & $2.54 \mathrm{~T}$ & $600.454 \mathrm{~B}$ & $1.32 \mathrm{~B}$ \\
Current ratio & 5.75 & 1.875 & 2.336 \\
Quick ratio & 4.833 & 1.59 & 1.219 \\
Debt ratio & 0.214 & 0.546 & 0.414 \\
Debt/Equity ratio & 0.27 & 1.19 & 0.71 \\
Beta & 0.85 & 2.06 & 2.01
\end{tabular}

The next part is about profitability. This article used total asset turnover ratios, profit margin ratios, ROA and ROE ratios to analyse the profitability of KTC. The total asset turnover rate represents the asset utilization efficiency of a company. The higher the total asset turnover is, the more efficient the utilization of asset. The total asset turnover rate for Kweichow Moutai is 0.49 , for TSLA the total asset turnover rate is 0.73 and for China Gold, it is 1.28. For profit margin ratios, It reflects the profit level of an enterprise in a certain period. Without the influence of other factors, the higher the gross profit rate of the company, the higher the total profit of the company. The profit margin ratio for Kweichow Moutai is $50.5 \%$, for TSLA the profit margin ratio is $3.18 \%$ and for China Gold, it is $17.98 \%$. For ROA, it is used to measure how much net profit is created per unit of assets. The ROA coefficient for Kweichow Moutai is $6.89 \%$, for TSLA the ROA coefficient is $1.67 \%$ and for China Gold, it is $2.1 \%$. Finally for ROE, it is used to measure the efficiency of companies using their own capital. The higher the index value, the higher the return of investment. The ROE coefficient for Kweichow Moutai is $8.29 \%$, for TSLA the ROA coefficient is $5.00 \%$ and for China Gold, it is $3.7 \%$.

Table 2. Profitability evaluation for different stocks.

\begin{tabular}{llll}
\hline Ratios & $\begin{array}{l}\text { Kweichow } \\
\text { Moutai }\end{array}$ & TSLA & China Gold \\
\hline Asset Turnover & 0.49 & 0.73 & 1.28 \\
Profit Margin & 0.505 & $3.18 \%$ & $17.98 \%$ \\
ROA & $6.89 \%$ & $1.67 \%$ & $2.10 \%$ \\
ROE & $8.29 \%$ & $5.00 \%$ & $3.70 \%$ \\
\hline
\end{tabular}

The third part is the market value relationship. this article used PE ratios, PB ratios, and PEG ratios, which would have an impact through analysis. The first is the $\mathrm{P}$ / $E$ ratio. $P E$ ratio is the data determined by stock price and earnings per share, it reflects the level of stock valuation, for example, if the PE ratio is very high, it means the stock valuation is very expensive, and there is a possibility that the stock is overvalued. The PE ratio of Kweichow Moutai is below 10, which means that maybe value investors may want to buy it. For TSLA and China Gold, both of them are above 10, this shows that the stock valuations of these two stocks are high. PB ratio refers to the ratio of stock price per share to net assets per share. The PB ratio for Kweichow Moutai is 14.60, for TSLA the PB ratio is 28.4 and for China Gold, it is 4.35 . And for the PEG ratio, when it is less than 1, the stock is considered undervalued. When the PEG ratio is greater than 1 , the stock is considered overvalued. From the research, this article found that the PEG ratio of Kweichow Moutai is 1.06. For TSLA, the PEG ratio is above 1 , and it is overvalued, the PEG ratio of China Gold is below 1 which means it is undervalued.

Table 3. Market value evaluation for different stocks.

\begin{tabular}{llll}
\hline Ratios & $\begin{array}{l}\text { Kweichow } \\
\text { Moutai }\end{array}$ & TSLA & China Gold \\
\hline Price/Earnings & 4 & 572.18 & 32.39 \\
P/B & 14.61 & 28.4 & 4.35 \\
PEG ratio & 1.06 & 3.39 & 0.87 \\
Insider Buying & $62.01 \%$ & $19.49 \%$ & $40.04 \%$ \\
\hline
\end{tabular}




\subsection{SHE framework}

Starbucks-Hilton-Estee Lauder (SHE) framework includes companies Starbucks, Hilton, and Estee Lauder.

The market capitalization of Starbucks was 233.24 million. The current ratio was 1.07 and the quick ratio was 0.84 . These two ratios measure a company's long-term solvency. Starbucks's total debt ratio was 0.88 , lower than 1, which means that its debt was lower than its equity. The profit margin, return on asset, and return on equity respectively were $4.18 \%, 3.5 \%$, and $13 \%$, which means that Starbucks's profitability was not so high. About Starbucks's market value, the PE ratio was 132.07, and the PEG was 0.74 , lower than 1 . The PB value per share was 0 which means that the development potential was not well.

There are two different possible investors. Firstly, the Growth investors. The final decision for this type of investor is that Starbucks's PEG ratio was $0.74(<1)$. Secondly, the Momentum investors. They hold the idea that the stock price is increasing steadily in the recent half year. On the other hand, there are two kinds of unlikely investors. The first one is the income investor because the profit margin of Starbucks was $4.18 \%$ $(<10 \%)$, and the second one is the value investor, for the $\mathrm{PE}$ ratio was 132.07 (>10).

Hilton was riskier than Starbucks because the total debt ratio was 1.30. Its net income, profit margin, and return on assets were negative. (We put all the data about the three companies' risk and profitability in figure (1), figure (2), and table (4) at the end of 3.2 SHE framework.) However, the PEG was 0.24, which means that Hilton was underestimated. The possible investors are growth investors, momentum investors, and value investors. Hilton's current market value is low. However, thinking of its global influence, value investors might have confidence in their future business. The unlikely investors are income investors because the profit margin of Hilton was $-3.30 \%$.

Estee Lauder performed best on the whole. It had the highest market capitalization ( $\$ 1.18$ billion), cash level (6.41 billion), and long-term solvency ratios (the current ratio was 2.11 and the quick ratio was 1.7 ). The total debt ratio was also less than 1 so that it was the least risky stock. Estee Lauder's profit margin was almost $10 \%$. Its ROA and ROE were both higher than those of the other two companies. Estee Lauder's PEG was 1.89 which was greater than 1 and lower than 2 . The possible investors are the same as Starbucks's - growth investors and momentum investors. Growth investors choose it for its PEG ratio was between 1 and 2, which is not that high. The unlikely investors are income investors and value investors. Income investors do not like it as the profit margin was $9.45 \%$ and value investors would think that the PE ratio of 78.86 was too big.
The following two figures (figure 1 and figure 2) compare the risk and profitability of the three companies.

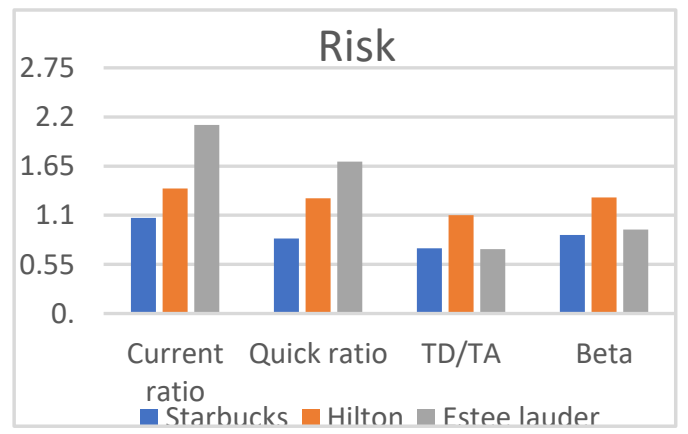

Figure 1 Different risk factor comparison for SHE framework.

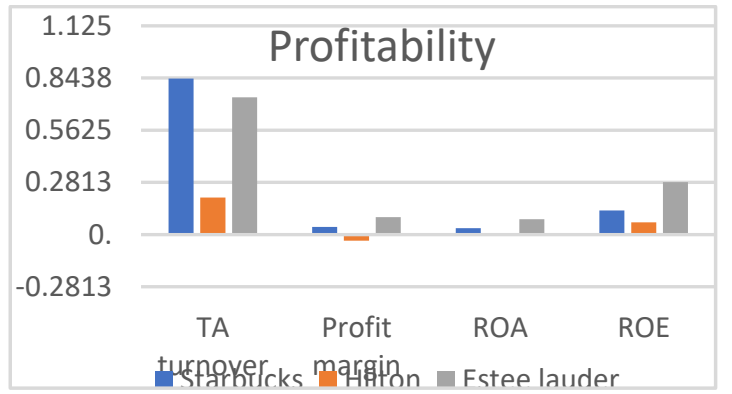

Figure 2 Different profitability factor comparison for SHE framework.

Table 4. Market value evaluation for SHE framework.

\begin{tabular}{llll}
\hline & Starbucks & Hilton & $\begin{array}{l}\text { Estee } \\
\text { Lauder }\end{array}$ \\
\hline $\begin{array}{l}\text { PE ratio } \\
\text { P/B value }\end{array}$ & 132.07 & 0 & 78.86 \\
$\begin{array}{l}\text { per share } \\
\text { Dividend }\end{array}$ & 16.76 & -21.69 & 19.53 \\
yield & $1.62 \%$ & 0 & $0.71 \%$ \\
PEG & 0.74 & 0.24 & 1.89 \\
$\begin{array}{l}\text { Insider } \\
\text { holding }\end{array}$ & $0.17 \%$ & $1.89 \%$ & $0.91 \%$ \\
\hline
\end{tabular}

\subsection{NGA framework}

Based on the initials of the 3 stocks, the NGA framework will explain our thought process on the analysis of these companies. Nike's stock price is currently 161.47 USD. For stock risk, it has a market cap of 203.69 million USD, a current ratio of 2.78, a quick ratio of 2.03 , a debt ratio of 1.19 , a debt to equity ratio of 0.48 , and a beta of 0.86 . For the profitability ratios, Nike has a total asset turnover of 0.52 , a profit margin of $11.5 \%$, a ROA of $3.78 \%$, a ROE of $18.35 \%$, and a net earnings margin of 6,247 million USD. For the market ratios, Nike has a P/E ratio above 10, a P/B ratio below 2, a dividend yield above 3\%, a PEG ratio below 1, a momentum above 200 day moving average, insider buying, and been buying back more than 5\%. By analyzing the data above this article can come to a conclusion that the investors who will be interested are defensive investors, momentum investors, and insiders. 
Amazon's stock price is currently 3733.51 USD. For stock risk, it has a market cap of 1.76 trillion USD, a current ratio of 1.05 , a quick ratio of 0.85 , a debt ratio of 2.13 , a debt to equity ratio of 0.51 , and a beta of 1.15 . For the profitability ratios, Amazon has a total asset turnover of 0.34 , a profit margin of $7.5 \%$, a ROA of $9.08 \%$, a ROE of $30.47 \%$, and a net earnings margin of 8.107 billion USD. For the market ratios, Amazon has a $\mathrm{P} / \mathrm{E}$ ratio above 10 , a $\mathrm{P} / \mathrm{B}$ ratio below 2 , a dividend yield below treasury yield, a PEG ratio above 1, a momentum below 200 day moving average, insider buying, and been buying back more than 5\%. By analyzing the data above this article can come to a conclusion that the investors who will be interested are institutional investors, momentum investors, and insiders.

General Motors' stock price is currently 58.2 USD. For stock risk, it has a market cap of 87.16 billion USD, a current ratio of 1.1, a quick ratio of 0.92 , a debt ratio of 3.23 , a debt-to-equity ratio of 2.44 , and a beta of 1.39 . For the profitability ratios, General Motors has a total asset turnover of 1.36 , a profit margin of $43.4 \%$, a ROA of $10.11 \%$, a ROE of $34.41 \%$, and a net earnings margin of 1.4 billion USD. For the market ratios, General Motors has a $\mathrm{P} / \mathrm{E}$ ratio above 10 , a $\mathrm{P} / \mathrm{B}$ ratio below 1 , a dividend yield below treasury yield, a PEG ratio above 1 , a momentum below 200 day moving average, insider buying, and hasn't been buying back more than 5\%. By analyzing the data above this article can come to a conclusion that the investors who will be interested are Growth investors and insiders.

As a conclusion, In the MTC framework, the stock that is most beneficial for investors to invest in is Kweichow Moutai, followed by China Gold, followed by TSLA. In the SHE framework, the stock that is most beneficial for investors to invest in is Estee Lauder, followed by Starbucks, followed by Hilton. And in the NGA framework, the stock that is most beneficial for investors to invest in is Nike, followed by Amazon, followed by general motors.

\section{CONCLUSION}

At present, it is very important to evaluate the future investment value of different companies, especially emerging enterprises. This article explored the investment opportunities of these nine firms: Kweichow Moutai, TSLA, China Gold, Starbucks, Hilton, Estee lauder, Nike, Amazon, General Motors. This article collected relevant financial data from Yahoo Finance, and evaluated them from three perspectives of risk, profitability, and market value relationship. The selected indicators include: market cap, quick ratio, current ratio, debt ratio, Debt/Equity ratio, Beta coefficient, Total Asset Turnover, Profit Margin, ROA, ROE, PE ratios, PB ratios, PEG ratios, momentum, insider buying and other indicators to help investors make investment decisions.
We set up comparisons separately in the three frameworks. In the KTC framework, investors like Kweichow Moutai most from all aspects. In the SHE framework, investors like Estee Lauder for all the three factors. In the NGA framework, investors prefer Nike for its lowest risk and its market value, and they like General Motor better for its highest profitability.

There also exists a limitation in our paper. This article only considered the comparative analysis of the company's financial indicators. There is no investment analysis based on the inherent logic of company growth, such as the dividend discount model and the weighted cost of the capital method. In order to be even more accurate in our analysis and successful in our investing, this article will focus on more factors that help select top quality stocks, and conduct more detailed research on specific companies in the future. This article will consider more quantitative models for decision analysis.

\section{REFERENCES}

[1] Lo, L. (2013). Can hedge funds time market liquidity?. Journal of Financial Economics.

[2] Benjamin Graham, David Dodd. Securities Analysis[M]. Hainan: Hainan Publishing House, 1999.

[3] Zhu Baoxian. Investment Science[M]. Beijing: Tsinghua University Press, 2002.17-18.

[4] Ball,R.J.,P. Brown. An Empirical Evaluation of Accounting Income Numbers. Journal of Accounting Research,1968,(Autumn):159-178.

[5] Lev. B. On the Usefulness of Earnings and Earnings Research: Lessons and Directions from Two Decades of Empirical Research. Journal of Accounting Research.1989,(27):153-201.

[6] S. Basu. Investment Performance of Common Stocks in Relation to Their Price-Earnings Ratios: A test of the Efficient Market Hypothesis. Journal of Finance. 1977,(6):63.

[7] D. A. Goodman, J. W. peavey. Industry Relative Price-Earnings Ratios as Indicators of Investment Returns. Financial Analysts Journal, 1983, 39:60.

[8] H. Levy, Z. Lerman. Testing P/E ratio filters with stochastic dominance.Journal of Portfolio Management.1985,11:31.

[9] A. J. Senchack, J. D. Martin. The relative performance of the PSR and PER investment strategies. Financial Analysts Journal. 1987,43(2):46.

[10] B. I. Jambs, K. N. Levy. On the Value of "Value". Financial Analysts Journal. 1988,44(4):47.Investment Returns. Financial Analysts Journal, 1983, 39:60. 